Tohoku J. exp. Med., 1981, 134, 125-139

\title{
Influence of Biliary Diversion upon Gastric Acid Secretion
}

\author{
Takeshi Sekine, HaJime Tsukui, Jin-Ichi Kameyama, \\ Iwao Sasaki and Toshio Sato \\ Department of Surgery, Tohoku University School of Medicine, \\ Sendai 980
}

Sekine, T., Tsukui, H., Kameyama, J., Sasaki, I. and Sato, T. Influence of Biliary Diversion upon Gastric Acid Secretion. Tohoku J. exp. Med., 1981, 134 (2), 125-139 — The influence of biliary diversion upon gastric acid secretion and the serum gastrin level was investigated in dogs with Heidenhain pouch. Biliary diversion was carried out by the following operative procedures: 1) External biliary fistula ( 3 dogs), ligation and division of the common bile duct and construction of an external biliary fistula by inserting a cannula into the gallbladder. 2) Roux-en-Y internal biliary fistula (6 dogs), ligation and division of the common bile duct and construction of an internal fistula (cholecystojejunostomy) by anastomosing the gallbladder to the jejunum $10 \mathrm{~cm}$ distal to the ligament of Treitz, with restoration of end-to-side jejunojejunostomy. In each dog, a test meal (Dog Food, $300 \mathrm{~g}$ ) was administered, and the gastric acid secretion and serum gastrin level were examined. In the external biliary fistula, the gastric acid secretion showed no increase after the test meal, while in the Roux-en-Y internal fistula the secretion from the Heidenhain pouch showed a significant increase in 4 of 6 dogs, with an increase rate of $110-330 \%$. In either the external biliary fistula or the Roux-en- $Y$ internal fistula, the serum gastrin level showed no significant change. However, in the dogs with the Roux-en- $Y$ internal fistula allotted for the observation periods of 4 to 5 months, the serum gastrin level at $3 \mathrm{hr}$ after the test meal was significantly higher than that at fasting. Further, in pursuit of the reproducibility of gastric acid secretion with the Roux-en- $Y$ internal biliary fistula in the course between the first and second Roux-en-Y internal fistulae, the gastric acid secretion markedly increased in the cases of the Roux-en-Y internal fistula, without definite changes in the level of serum gastrin. Acute gastric ulcer developed in 2 of 6 dogs with the Roux-en- $Y$ internal biliary fistula, but no fat indigestion was caused. These results suggest that gastric hypersecretion induced by biliary diversion may prove the possibility of presence of gastric secretagogue, different from gastrin, released in the upper jejunum.

biliary diversion; internal biliary fistula; gastric acid secretion; serum gastrin level

Biliary-intestinal anastomoses are used for reconstruction of the biliary tract. It has been pointed out that the surgical procedure for reconstruction of the biliary tract, particularly choledochojejunostomy, is likely to give rise to peptic ulcer. Recently, McArthur and Longmire (1971) reported an increased incidence of peptic ulcer in a relatively large series of patients who had undergone choledochojejunostomy for benign biliary obstruction. However, the possible

Received for publication, October 13, 1979. 
relationship between peptic ulcer development and biliary diversion after biliaryintestinal anastomosis still remains obscure. In an attempt to elucidate the influence of biliary diversion or interruption of bile flow into the duodenum upon gastric acid secretion, the present experiments were undertaken to investigate the changes of gastric acid secretion as well as the levels of serum gastrin after two different types of biliary diversion in dogs with Heidenhain pouch.

\section{Materials ANd Methods}

A total of 9 adult mongrel dogs of both sexes, weighing 10 to $17 \mathrm{~kg}$ and ranging in age from 2 to 6 years, were used. A Hedienhain pouch was constructed in each of these dogs by inserting a Gregory cannula through the anterior wall into the body of the stomach. The dogs were fed a standard diet with a tablespoon of table salt added to feeding.

Experiments were begun aftcr the dogs were allowed to recuperate from the operation for at least 3 to 4 weeks. Before the experiment they were fasted for 18 to $24 \mathrm{hr}$ but allowed free access to water. Studies were conducted usually twice a week or on alternate days.

The secretory response of the Heidenhain pouch by stimulation with a subcutaneous injection of $0.1 \mathrm{mg} / \mathrm{kg}$ of histamine diphosphate and an intravenous injection of $0.5 \mathrm{U} / \mathrm{kg}$ of regular insulin was checked in all dogs in order to confirm that the pouch is a denervated one. In each dog, a test meal (Dog Food, $300 \mathrm{~g}$ ) was administered, and the following tests were carried out.

Gastric acid secretion. Gastric juice from the Heidenhain pouch was collected in a rubber bag attached securely to the cannula for 5 to $6 \mathrm{hr}$. The volume of each sample was measured and the concentration of acid was determined by titration to $\mathrm{pH} 7.0$ with 0.1 $\mathrm{N} \mathrm{NaOH}$ on a Radiometer autotitrator. Acid output was expressed as $\mathrm{mEq} / 5,6-24$, and $24 \mathrm{hr}$.

Serum gastrin level. At the same time, blood was taken from the external jugular vein before and at 10,30, 60, and $180 \mathrm{~min}$ after administration of a test meal for determination of the level of serum gastrin. Serum gastrin concentration was determined by radioimmunoassay, utilizing Gastrin-Radioimmunoassay Kit (CIS). The values obtained at this period were used as control. After the control period, the dogs were divided into two groups and each dog underwent one of the following procedures: External biliary diversion (external fistula); in 3 dogs, the common bile duct was ligated and divided just proximal to its entry into the duodenum. A cannula was placed in the gallbladder as an external biliary fistula and brought to the exterior through a stab wound (Fig. 1). And, internal biliary diversion (Roux-en-Y internal fistula); in 6 dogs, the common bile duct was ligated and divided close to the duodenum. The dome of the gallbladder was anastomosed, end-toend, to a Roux-en-Y loop of the jejunum $10 \mathrm{~cm}$ distal to the ligament of Treitz. The jejunal loop was approximately $40 \mathrm{~cm}$ in length and a jejunojejunal anastomosis was made, end-to-side (Fig. 1). In one of the dogs used for this procedure, the jejunum was transected just proximal to the jejunojejunostomy, and the proximal end was closed and the distal end was anastomosed, end-to-side, to the duodenum.

After recovery periods of 3 to 4 weeks, the secretion from the Heidenhain pouch was again collected and measured as before, and the level of serum gastrin was observed on the same dogs. Observations were made in the cases of external biliary diversion for 2 months before and 6 weeks after the external fistula, while in the cases of internal biliary diversion, the observation periods before and after the Roux-en- $\mathrm{Y}$ internal fistula were 2 months each in 3 cases and 4 to 5 months each in 3 others. In the cases of the external fistula showing a considerable loss of body fluid, care was taken to prevent serum electrolyte depletion.

In all dogs, liver functions were checked at least every 4 weeks during the course of the experiment. At the end of the experiment, the dogs were sacrificed, and the stomach, duodenum, jejunum, and liver were examined macroscopically and microscopically. 

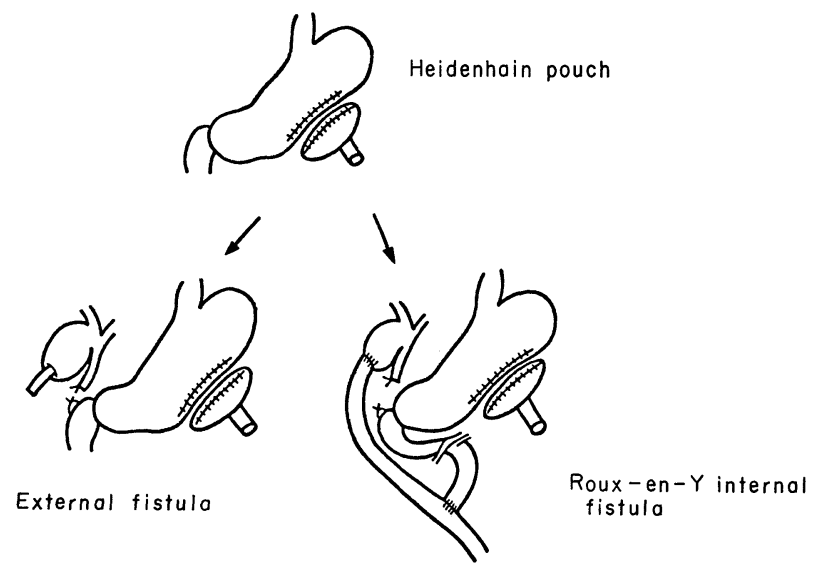

Fig. 1. Surgical procedures in the two groups of dogs with Heidenhain pouch and external or Roux-en-Y internal fistula.

Further, the patency of the biliary-intestinal anastomosis was confirmed.

The measured values were expressed as mean士s.e.m. Statistical comparisons were made with Student's $t$-test for unpaired values and statistical significance was assigned to values with $p<0.05$.

\section{RESULTS}

\section{Gastric acid secretion}

Acid concentration. The acid concentration in response to the test meal and histamine in one case each of the two groups of dogs is shown in Fig. 2. In the cases
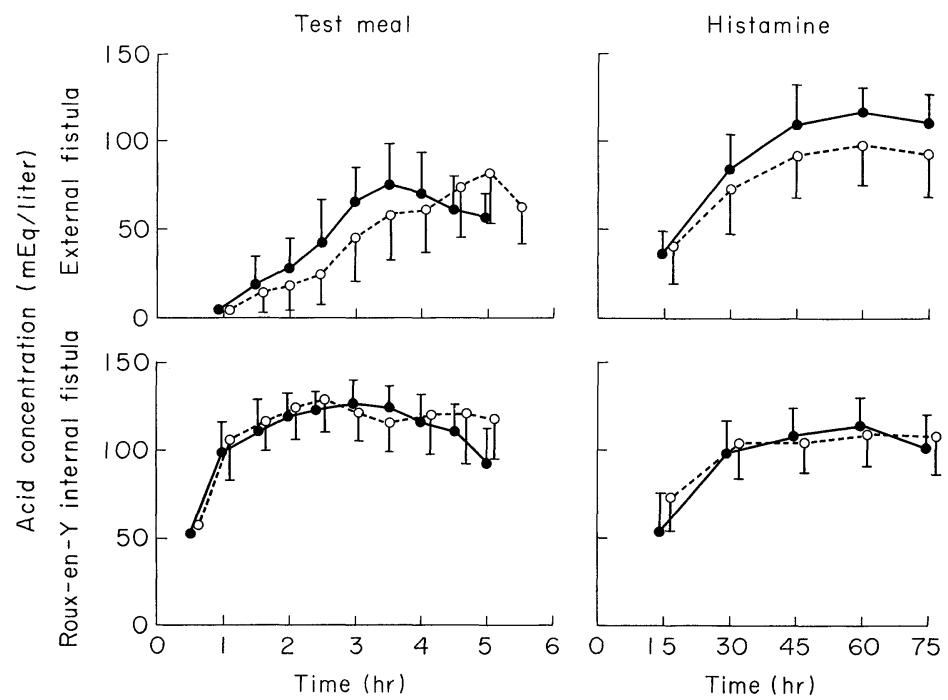

Fig. 2. Acid concentration after test meal and histamine. dogs with external or Roux-en-Y internal fistula. 
of external biliary diversion and internal biliary diversion, each dog received stimulations with the test meal and histamine 10 times and 5 times, respectively. In the cases of external biliary diversion, the acid concentration in response to the test meal reached the maximum after $5 \mathrm{hr}$, while after 3 to $4 \mathrm{hr}$ in the control. The highest value of acid concentration averaged $75 \mathrm{mEq} /$ liter, showing no significant difference between the group of external fistula and the control. In the cases of stimulation with histamine, the highest value of acid concentration averaged 100 $\mathrm{mEq} /$ liter, showing no significant difference from the control. In the cases of internal biliary diversion, the highest value of acid concentration averaged 115 $\mathrm{mEq} /$ liter in both the test meal and histamine stimulation, showing no significant difference from the control.

Acid output. Acid output in response to the test meal is shown in 3 dogs each from the groups of external biliary diversion and internal biliary diversion (Figs. 3 and 4).

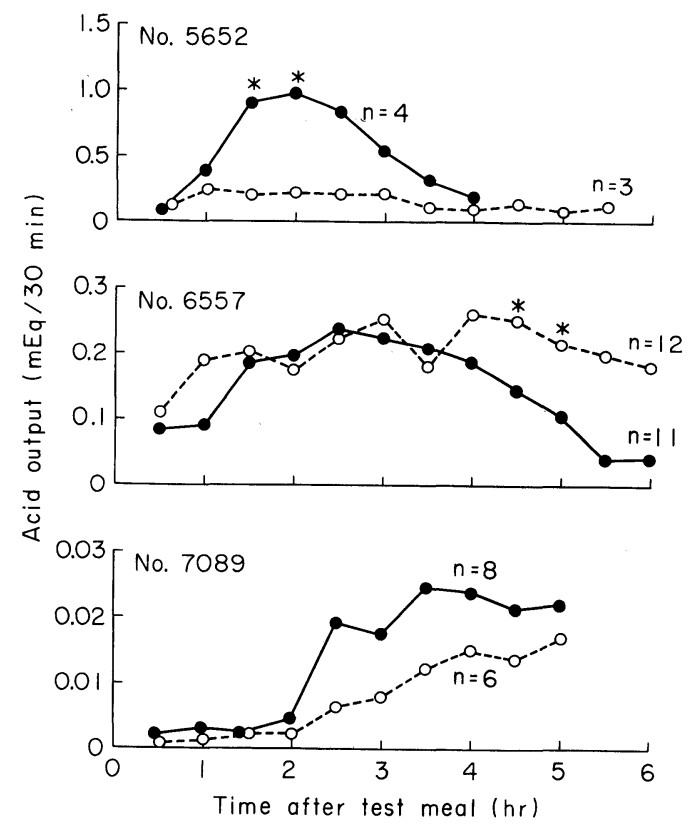

Fig. 3. Acid output after test meal in dogs with an external biliary fistula.

$\bullet-\bullet$, control; $\bigcirc-\cdots$ o, external fistula. $* p<0.05$.

Acid output was significantly increased at $4 \mathrm{hr}$ and later in a dog that had shown transient jaundice (total bilirubin value, $2.4 \mathrm{mg} / 100 \mathrm{ml}$ ) immediately after the external fistula, while in 2 others acid output decreased after formation of the external fistula. Particularly in one of the two, the external fistula induced a significant reduction of acid output at $11 / 2$ and $2 \mathrm{hr}$. On the other hand, in the cases of the Roux-en-Y internal fistula, acid output, though its maximum lagged to occur behind the control, showed a significant increase at $31 / 2$ 


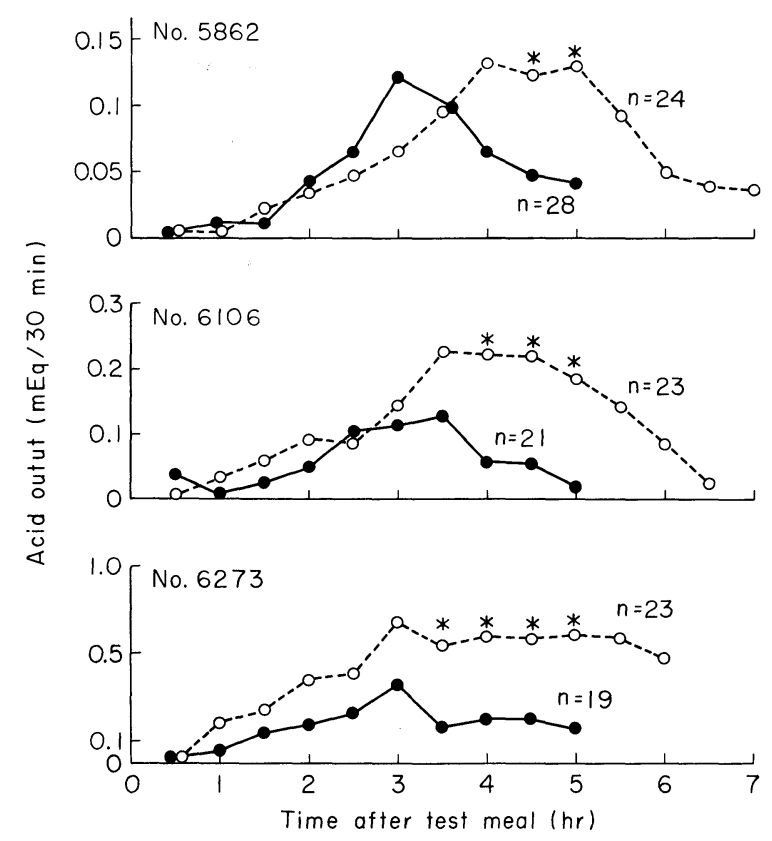

Fig. 4. Acid output after test meal in dogs with Roux-en-Y internal fistula.

$\bullet-\bullet$, control; $\bigcirc-.--\circ$, Roux-en-Y internal fistula. ${ }^{*} p<0.05$

or $4 \mathrm{hr}$ after the stimulation. After administration of the test meal, the acid secretion almost ceased in the control at $5 \mathrm{hr}$, but it continued in the cases of the Roux-en-Y internal fistula for more than $5 \mathrm{hr}$.

Acid output $(\mathrm{mEq} / 5 \mathrm{hr})$ in the two groups of dogs is shown in Figs. 5 and 6. In 3 dogs with the external fistula (Fig. 5), the acid outputs averaged 4.16, 1.71, and $0.14 \mathrm{mEq} / 5 \mathrm{hr}$, respectively. After the external fistula, the values turned to average $1.50,2.10$, and $0.06 \mathrm{mEq} / 5 \mathrm{hr}$, respectively. With the exception of a transient jaundice case, the other 2 cases showed a significant increase in acid output. On the other hand, in the 6 dogs with the Roux-en-Y internal fistula (Fig. 6),
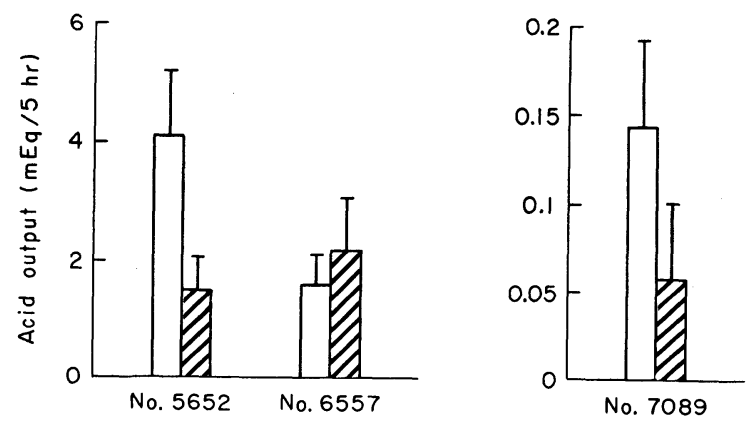

Fig. 5. Acid output after test meal in dogs with an external biliary fistula. before; $\mathbb{Z Z}$ after. 


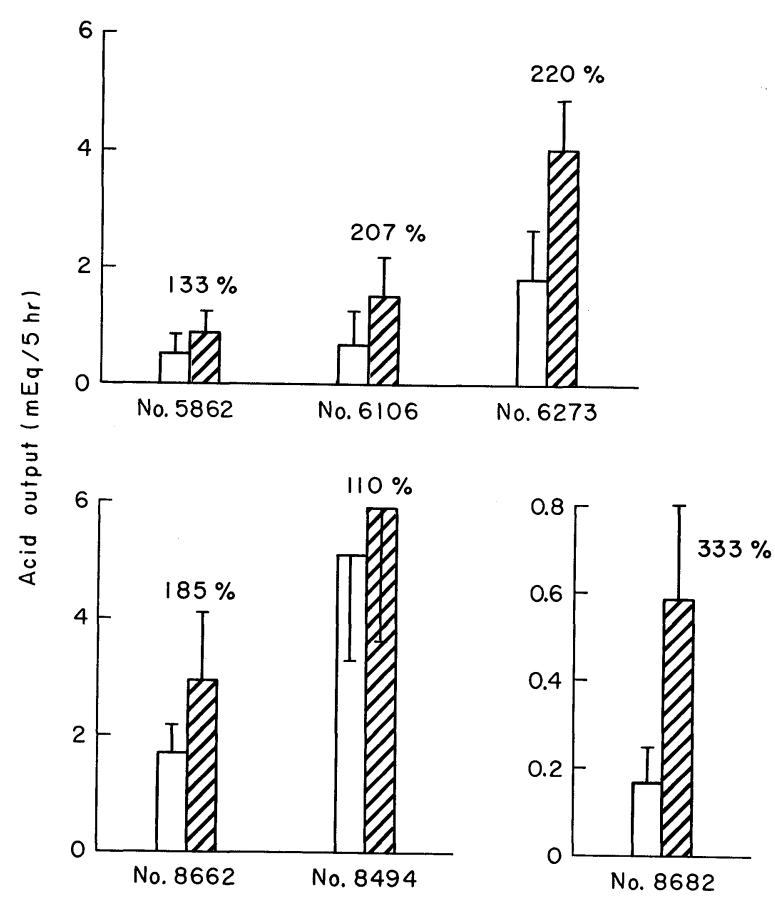

Fig. 6. Acid output after test meal in dogs with Roux-en-Y internal fistula. before; VIIA after.

3 dogs undergoing the observation periods of 4 to 5 months after the Roux-en-Y internal fistula showed an average value of acid output of $0.68,1.43$, and $4.02 \mathrm{mEq} /$ $5 \mathrm{hr}$, respectively, surpassing the control values of $0.51,0.69$, and $1.83 \mathrm{mEq} / 5 \mathrm{hr}$. The statistical differences from the control values were significant for the latter 2 cases, but not significant for the remaining one. In 3 others undergoing the observation periods of 2 months after the Roux-en-Y internal fistula, the acid outputs in the control averaged $1.65,5.39$, and $0.15 \mathrm{mEq} / 5 \mathrm{hr}$, respectively, which turned to $2.68,5.56$, and $0.73 \mathrm{mEq} / 5 \mathrm{hr}$ after the Roux-en-Y internal fistula. Acid outputs showed a significant increase over the control in 2 dogs, but not a significant increase in the other one which had bleeding from the Heidenhain pouch after the Roux-en-Y internal fistula and showed an acid concentration decreasing from the control average of $125 \mathrm{mEq} /$ liter to an average of $71 \mathrm{mEq} /$ liter after the Roux-en-Y internal fistula. After successful hemostasis 2 months later, the acid output in this case averaged $6.14 \mathrm{mEq} / 5 \mathrm{hr}$, showing a tendency to outstrip the control value. The rates of increase in acid output over the control value in these 6 cases of the Roux-en- $Y$ internal fistula were $110-330 \%$ on average. The volumes of acid secreted in $5 \mathrm{hr}$ in the 6 dogs with the Roux-en-Y internal fistula increased over the control value independent of the observation periods. In 4 of the 6 dogs the rates of increase were significant. 
Changes in the level of serum gastrin

Changes in serum gastrin level in dogs with the external fistula and those with the Roux-en-Y internal fistula are shown in Figs. 7 and 8 . In the dogs with the external fistula, the levels of serum gastrin at fasting averaged 20.2,36.0, and 38.9 $\mathrm{pg} / \mathrm{ml}$, but $180 \mathrm{~min}$ after administration of the test meal, they averaged 32.0, 38.2, and $62.6 \mathrm{pg} / \mathrm{ml}$, respectively. Except the last case showing transient jaundice after the external fistula, the other 2 cases had 180-min levels nearly reverting to their fasting levels. The changes of serum gastrin level in the external fistula were almost identical in tendency with those in the control (Fig. 7). In 3 dogs with the Roux-en-Y internal fistula allotted to the observation periods of 4 to 5 months, the levels of serum gastrin at fasting averaged $45.1,48.5$, and $29.1 \mathrm{pg} / \mathrm{ml}$, and at 180 min after the test meal 90.2, 93.8 and $52.6 \mathrm{pg} / \mathrm{ml}$, respectively. Also in 3 others for the observation periods of 2 months, the serum gastrin levels were higher at $180 \mathrm{~min}$ than at fasting, but they showed no significant differences from the control levels (Figs. 8 and 9).

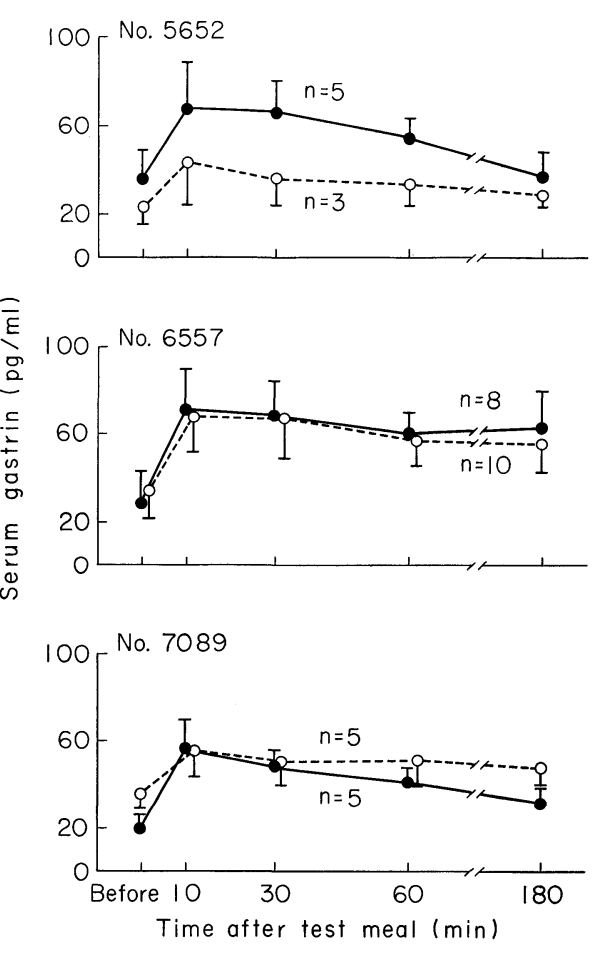

Fig. 7.

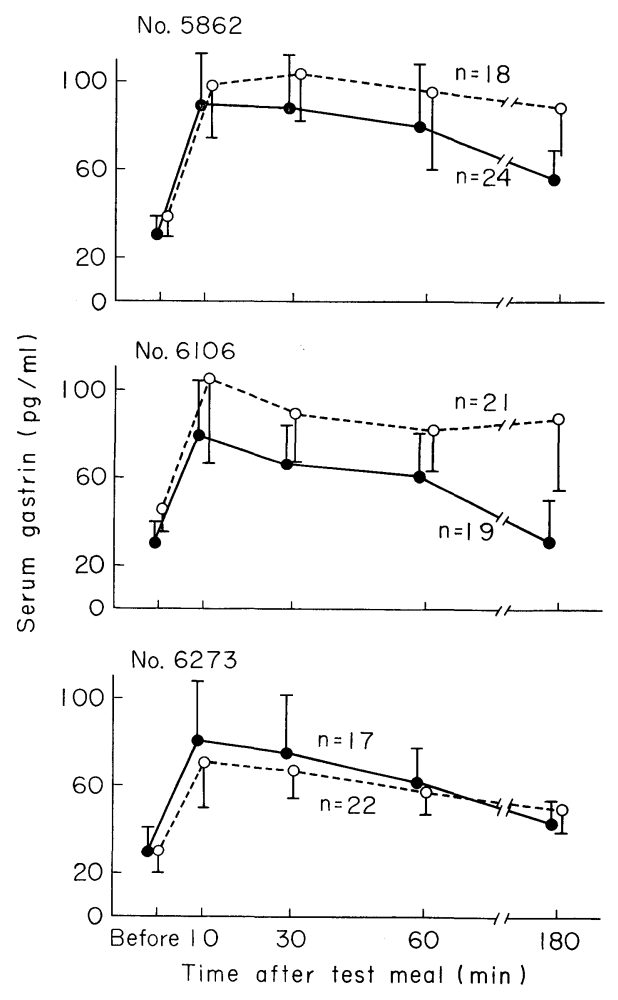

Fig. 8.

Fig. 7. The change in the level of serum gastrin following the external biliary fistula.

$\bullet-\bullet$, control; O-..-O, external fistula.

Fig. 8. The change in the level of serum gastrin following the Roux-en-Y internal fistula (observation period of 2 months).

$\bullet-\bullet$, control; O----o, Roux-en-Y internal fistula. 


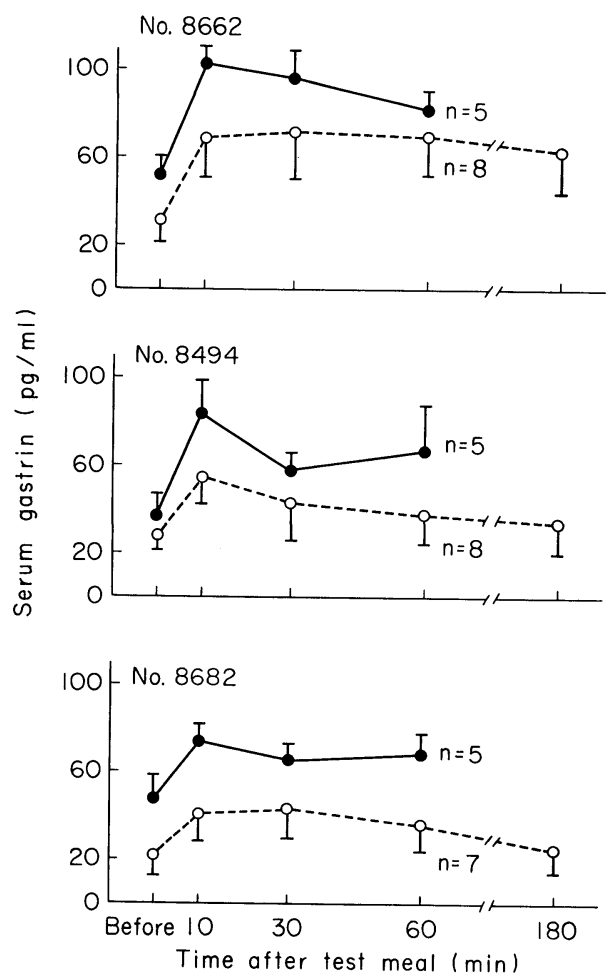

Fig. 9. The change in the level of serum gastrin following the Roux-en-Y internal fistula (observation periods of 4 to 5 months).

$\bullet-\bullet$, control; ○-..-०, Roux-en-Y internal fistula.

Reproducibility of gastric acid secretion in cases of the Roux-en-Y internal fistula

Using one dog with the Roux-en-Y internal fistula that showed a significant increase in acid output in the observation periods of 4 to 5 months, reproducibility of gastric acid secretion was investigated as illustrated in Figs. 10 and 11. After gastric acid secretion was confirmed markedly increasing with the Roux-en-Y internal fistula (II) as compared to the control (I), the jejunum was transected just proximal to the jejunojejunostomy, and the distal jejunal end was anastomosed, end-to-side, to the duodenum (III) to allow bile to pass through the jejunal loop into the duodenum. Then using the same jejunal loop, intestinal continuity in the second Roux-en-Y internal fistula was restored by end-to-side jejunojejunal anastomosis (IV). The acid output was $0.69 \mathrm{mEq} / 5 \mathrm{hr}$ on average in the control (I), $1.43 \mathrm{mEq} / 5 \mathrm{hr}$ with the first Roux-en-Y internal fistula (II), $1.06 \mathrm{mEq} / 5 \mathrm{hr}$ with the jejunal loop anastomosis to the duodenum (III), and $3.35 \mathrm{mEq} / 5 \mathrm{hr}$ with the second Roux-en-Y internal fistula (IV (1)). The second Roux-en-Y internal fistula (IV (1)) had about 3 times as high acid output as did the jejunal loop anastomosis to the duodenum (III) resuming the flow of bile into the duodenum.

A comparison of acid output between the first Roux-en-Y internal fistula (II) 


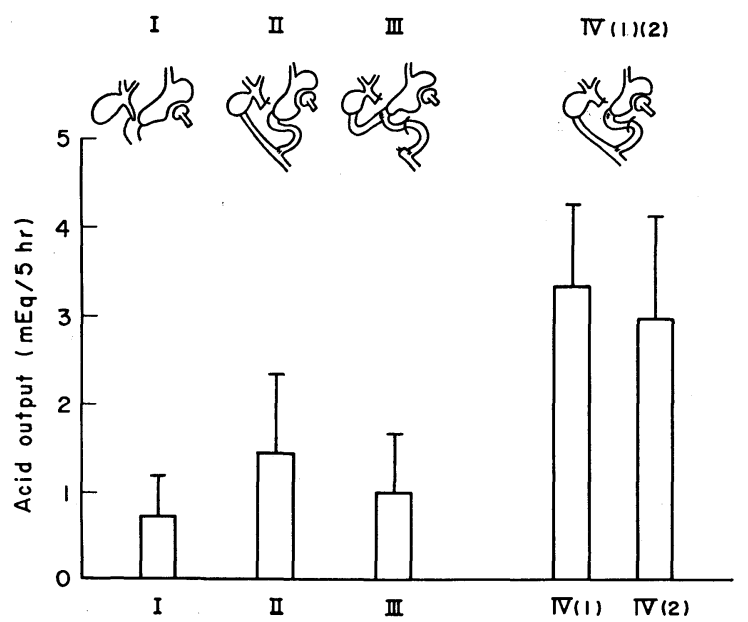

Fig. 10. Reproducibility of gastric acid secretion in one dog with the Roux-en-Y internal fistula.

I, control $(n=21)$; II, Roux-en-Y internal fistula (1st) $(n=23)$; III, jejunal loop anastomosis to the duodenum $(n=8)$; IV(1), Roux-en-Y internal fistula (2nd), observation periods of 2 months $(n=5) ; \operatorname{IV}(2)$, the same as above, observation periods of 3 to 7 months $(n=14)$.

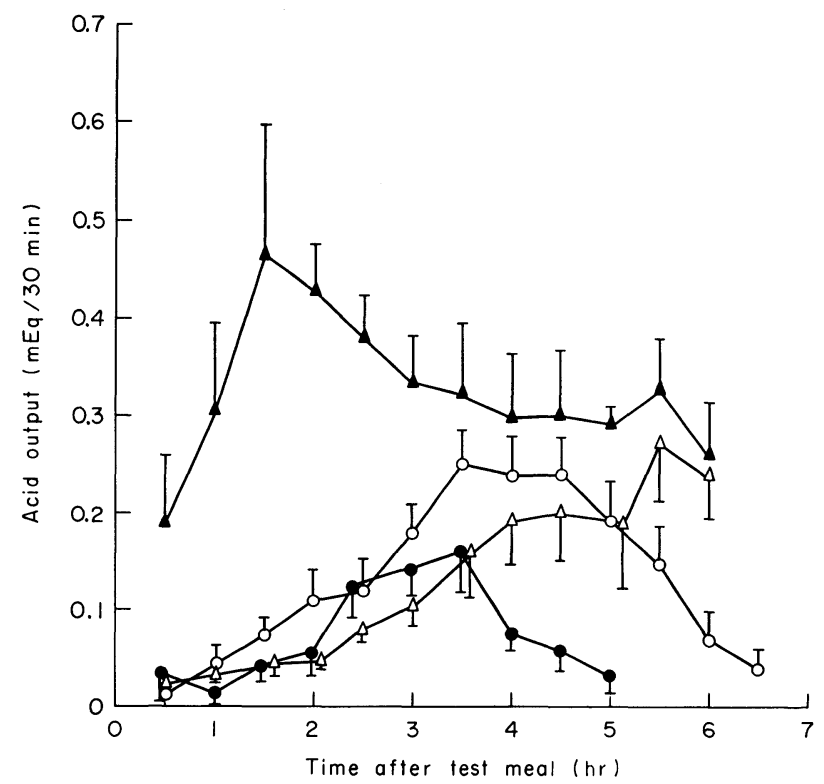

Fig. 11. Reproducibility of gastric acid secretion in one dog with the Roux-en-Y internal fistula.

$\bullet-\bullet$ I, control $(n=21)$; ○$\Delta-\Delta$, III, jejunal loop anastomosis to the duodenum $(n=8)$; $\Delta-\Delta$, IV (1), Rouxen-Y internal fistula (2nd), observation periods of 2 months $(n=5)$. 
and the jejunal loop anastomosis to the duodenum (III) showed that within $5 \mathrm{hr}$ after administration of the test meal, the decrease in acid output was less remarkable with the first Roux-en-Y internal fistula (II) than with the jejunal loop anastomosis to the duodenum (III). However, after $5 \mathrm{hr}$, the acid output turned to decrease markedly with the first Roux-en-Y internal fistula (II) against the tendency of its increase remaining with the jejunal loop anastomosis to the duodenum (III). After 2 months of the observation period with the second Roux-en-Y internal fistula (IV (1) ), and in the observation periods of 3 to 7 months (IV (2)), the acid output showed an average value of $2.97 \mathrm{mEq} / 5 \mathrm{hr}$, indicating a marked increase continuing over the control value.

\section{Reproducibility of the level of serum gastrin with the Roux-en-Y internal fistula}

In the same dog as used for the foregoing experiment, changes in the level of serum gastrin after the test meal for the reproducibility of gastric acid secretion were examined (Fig. 12). The levels of serum gastrin at fasting averaged $32.9 \mathrm{pg} / \mathrm{ml}$ in the control (I) and $40.9 \mathrm{pg} / \mathrm{ml}$ in the state of jejunal loop anastomosis to the duodenum (III), and their highest 10-min levels averaged 84.9 and $96.6 \mathrm{pg} / \mathrm{ml}$, respectively. There was no significant difference between the control and jejunal loop anastomosis. On the other hand, the levels of serum gastrin in the states of the first (II) and the second Roux-en-Y internal fistula (IV (1) and IV (2)) averaged $45.8,25.3$, and $56.1 \mathrm{pg} / \mathrm{ml}$, respectively, at fasting, and $111.2,50.7$, and $114.0 \mathrm{pg} / \mathrm{ml}$ $10 \mathrm{~min}$ after administration of the test meal, while their 180-min levels were 93.8 , 35.7 , and $78.0 \mathrm{pg} / \mathrm{ml}$. It was evident that the levels of serum gastrin at fasting and after the test meal were significantly lower in IV (1) state than in II or IV (2) state.

However, there were no significant differences between the levels at fasting, and at 10 and 180 min after the test meal either in the state of II or IV (2), nor were

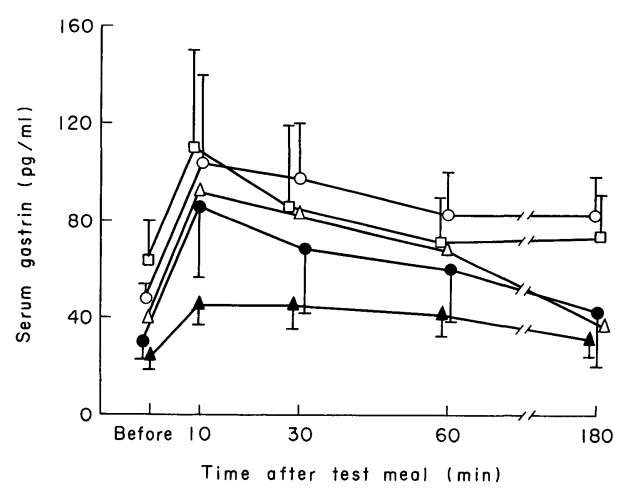

Fig. 12. Reproducibility of the level of serum gastrin with the Roux-en-Y internal fistula.

$\bullet-\bullet$, I, control $(n=19)$; ○- $\mathrm{O}$, II, Roux-en-Y internal fistula (1st) $(n=21) ; \Delta-\Delta$, III, jejunal loop anastomosis to the duodenum $(n=7) ; \mathbf{\Delta} \longrightarrow \mathbf{\Delta}$, IV(1), Roux-en-Y internal fistula (2nd), observation periods of 2 months $(n=5)$; $\square-\square, \operatorname{IV}(2)$, the same as above, observation periods of 3 to 7 months $(n=13)$. 
there any distinct trends of change in the level distinguishing between these two states. On the other hand, in IV (1), the levels of serum gastrin averaged 25.3 $\mathrm{pg} / \mathrm{ml}$ at fasting and $35.7 \mathrm{pg} / \mathrm{ml}$ at $180 \mathrm{~min}$; the latter was significantly higher than the former as in II.

\section{Pathological findings on the stomach, duodenum, liver and the Heidenhain pouch}

Among the 6 dogs with the Roux-en-Y internal fistula, 2 developed multiple acute ulcers (U1-II) in the pyloric gland area. In dogs with either the external fistula or the Roux-en-Y internal fistula, the common bile duct was dilated to 1.0 $\mathrm{cm}$ in diameter at largest, but the site of cannula inserted into the gallbladder and the anastomotic site of cholecystojejunostomy were sufficiently patent. There was no gross evidence of fatty liver, nor was there any finding of jaundice or liver swelling. Microscopically, there was no inflammation of the bile duct or liver fibrosis.

\section{Liver function}

None of the dogs with either the external fistula or the Roux-en-Y internal fistula - except for a dog that developed transient jaundice - showed values exceeding $0.7 \mathrm{mg} / 100 \mathrm{ml}$ for total bilirubin, 84 for SGOT, 141 for SGPT, or 33.6 $\mathrm{K}-\mathrm{A}$ units for Al-P.

\section{Others}

In the dogs with the Roux-en-Y internal fistula, similarly to the control, serum turned strongly white 1 to $3 \mathrm{hr}$ after administration of the test meal, but the turbidity disappeared at $5 \mathrm{hr}$ or later.

\section{Discussion}

There has been a subject of interest in the interruption of bile flow into the duodenum, or biliary diversion, which is likely to develop hypersecretion of gastric acid and peptic ulcer in the patients. Recently, McArthur and Longmire (1971), treating patients with benign biliary obstruction with choledochojejunostomy (Rouxen-Y) in 97 cases and with cholecystoduodenostomy in 39 cases, observed the development of postoperative peptic ulcer in 10 of 97 cases in the former group. Subsequent reports have further pointed out that biliary tract reconstruction procedures such as cholecystojejunostomy (Roux-en-Y) and external biliary fistula for patients with obstructive jaundice or biliary obstruction still leave various problems to be elucidated regarding the effect of biliary diversion upon gastric acid secretion. Patients with diseases requiring reconstruction of the biliary tract are often complicated with hepatic disroders induced by bile stagnation and infection. In addition, the interruption of bile flow into the duodenum, or biliary diversion, must be considered with relation to the possible influences of (1) degradation in the neutralizing ability of duodenal juice, (2) indigestion of fat, and (3) decrease in the production and release of gastric inhibitory hormone from 
the duodenum or upper small intestine. We pursued these problems with the final aim of finding a clue to the mechanism for hypersecretion of gastric acid in biliary diversion.

Liver damage has been pointed out to be an important factor. In the present study with cholecystojejunostomy (Roux-en-Y) in dogs, postoperative hypersecretion of gastric acid could not be considered without liver damage as an etiologic factor. Either with the external biliary fistula or with the Roux-en-Y internal fistula, no dogs developed severe jaundice during the observation periods, except one with the external fistula showing transient jaundice. Liver failure identified in the examination of liver function was notably slight in dogs with the external fistula compared to dogs with complete obstruction of the common bile duct, whereas values of their total bilirubin and Al-P were evidently higher than those in the control. Silen et al. (1962), producing obstructive jaundice in dogs with Heidenhain pouch by inducing obstruction of the common bile duct, observed that the acid output from the Heidenhain pouch was closely correlated with the function and microscopic alterations of the liver, and that the hypersecretion of gastric acid continued even after decompressing the bile duct. They emphasized the release of a histamine-like substance from the damaged liver. Heimburg and Hallenbeck (1964) cited an associated factor in the reduced inactivation of histamine in the liver. Kurokawa (1970), on the other hand, pointed out the reduced activation of histaminase in the liver as a factor inducing peptic ulcer in dogs with the liver damaged by carbon tetrachloride. And, among the major important factors for hypersecretion of gastric acid after small bowel resection, the secondary impairments of the liver function have been considered, including the fatty liver induced by disorder of the hepato-intestinal circulation of bile due to fat indigestion. Menguy (1962), in his experiments with Mann-Williamson ulcer, performed biliary diversions to the lower ileum, and found no increase in the value of Al-P but a marked rise in the value of BSP, which continued until 5 weeks after bile and pancreatic juice were returned to the duodenum. Based on this finding, Menguy (1962) suggested that gastric hypersecretion was related to liver disease (fatty liver) and to diminished ability of the liver to destroy histamine absorbed from the intestine. In the present experiments with the external fistula, the dog which showed transient postoperative jaundice could improve its liver function 1 week after decompressing the bile duct, but the hypersecretion of gastric acid continued. Acceptance of these data could rule out the liver damage as a factor responsible for the gastric hypersecretion, and once the liver damage has occurred, the influence of liver damage on gastric acid secretion may remain unabated even if the influence has been judged to be slight in the light of histology and function of the liver. On the other hand, the ability of duodenal juice to neutralize gastric acid with bile has been indicated to be less marked than previously thought. The bile in the duodenum has $\mathrm{pH}$ not so strongly alkaline with a negligible contribution to duodenal buffering of gastric acid only less than $20 \%$. 
With regard to fat indigestion and the concomitant action of gastric inhibitory hormone secreted in the duodenum or upper small intestine, Menguy (1961), in his experiments with 4 dogs, performing cholecystoileostomy (Roux-en-Y), found gastric acid secretion commencing within 1 to 2 weeks after the operation. Then in 2 of them, he performed cholecystoduodenostomy and observed hypersecretion of gastric acid lasting as long as 75 days thereafter. Based on this finding, Menguy (1961) insisted that hypersecretion of gastric acid after cholecystoileostomy (Roux-en-Y) should be attributed to some factors other than loss of intestinal inhibition related to indigestion of fat due to the interrupted bile flow into the duodenum. Breen et al. (1968) performed choledochojejunostomy (Roux-en-Y) in 12 dogs with Heidenhain pouch, and found an increase in gastric acid secretion. Furthermore, hypersecretion of gastric acid was significant early on the 5th day of operation in 4 to 5 dogs with cholecystojejunostomy (Roux-en-Y), contrasted with no increase of the secretion in dogs with cholecystoduodenostomy. In search of the mechanism for hypersecretion of gastric acid after cholecystojejunostomy (Roux-en$\mathrm{Y}$ ), they pointed out that the loss of body weight was markedly greater in dogs with cholecystojejunostomy (Roux-en-Y) than in those with cholecystoduodenostomy, and suspected that the possible fat indigestion and insufficiency in emulsion of fat due to the lack of bile, particularly bile salts, eventually worked together to reduce the production of gastric inhibitory hormone in the duodenum or upper small intestine. Inducing biliary diversion by the external biliary fistula and internal biliary fistula (side-to-side cholecystoileostomy), Albo et al. (1965) studied on gastric acid secretion and further, providing the reversible biliary fistula, investigated the influence of the stimulation with secretin upon gastric acid secretion under the presence or absence of bile flow into the duodenum. The results showed that the external or internal biliary fistula abolished the inhibitory effect of secretin upon food-induced secretion from the Heidenhain pouch, and that the instillation of bile into the duodenum alone or during the administration of secretin caused inhibition of food-induced secretion. Nahrwold and Grossman (1967) noted that a 3 -hr external biliary diversion in the dog brought about a significant reduction in Heidenhain pouch secretion with stimulation in response to food.

As for fat indigestion, the present experiments showed that the changes of fat in blood after administration of a test meal could not distinguish between the cases of the Roux-en-Y internal fistula and the control, failing to provide any plausible explanation of the prominent hypersecretion of gastric acid.

On the other hand, Kihl and Landor (1975), in their experiments with 6 dogs, performed the external biliary fistula and the external biliary fistula with ThiryVella loop $90 \mathrm{~cm}$ of distal ileum in the same dog, and found that with the external biliary fistula through the ileal loop, gastric acid secretion increased (19-105\%) but bile secretion decreased $(30-40 \%)$, each distinctly greater than with the external biliary fistula. Then pointing out the absorption of bile in the ileum leading to inhibition of gastric acid secretion, they suggested that impairment in 
hepato-intestinal circulation of bile may exert some influence on gastric acid secretion. Wickbom et al. (1974) carried out cholecystoileostomy, side-to-side, and Roux-en-Y anastomosis, in the same dog with Heidenhain pouch. They found that total external diversion of bile brought about a decrease in gastric acid secretion, while simple diversion of bile to the distal ileum via a Roux-en-Y segment of ileum caused a significant increase. As regards such a difference in gastric acid secretion, they suggested the release of an unknown substance which influences gastric acid secretion, or the absorption of components of bile not normally absorbed or absorbed in abnormal ratio. Landor et al. (1970), however, providing the external biliary fistula in dogs with Heidenhain pouch, observed that the total external biliary diversion did not bring about an increase in gastric acid secretion. Further, additional resection of the small bowel caused a significant increase of gastric acid secretion. Although they concluded that the hypersecretion of gastric acid in these dogs was independent of the presence or absence of bile, the problem still remains complicated since the lack of gastric inhibitory hormone in the upper jejunum might be accounted for this hypersecretion after resection of the small intestine.

On the other hand, Orloff et al. (1970), noting a high incidence of peptic ulcer in patients with liver cirrhosis or portacaval shunt, postulated the existence of some substance responsible for gastric acid secretion and for the profound gastric hypersecretion. Further, they provided Heidenhain pouch and Thiry-Vella fistula to dogs in pursuit of the intestinal phase of gastric acid secretion. Recently, they (1976) could isolate and extract from the intestinal mucosa of hogs a substance stimulating gastric acid secretion - gastric secretagogue. According to them, this substance is distinctly different from intestinal gastrin and dissimilar to CCK$\mathrm{PZ}$ because it is significantly inactivated by passage through the liver, yet it is as strong as gastrin in stimulating gastric acid secretion. Slaff (1974), perfusing the small intestine with liver extract, speculated the existence of a substance stimulating gastric acid secretion. This substance, different from CCK-PZ, was named "entero-oxyntin", proposed by Grossman (1974). Debas et al. (1975), obtaining identical experimental results, reported the substance strongly stimulating gastric acid secretion without producing an increase in the level of serum gastrin and concluded it to originate in the jejunum. The existence of "entero-oxyntin" as a substance stimulating gastric acid secretion in the intestinal phase was also confirmed by Way et al. (1975). Whether "entero-oxyntin" proposed by Slaff (1974), Grossman (1974) and Debas et al. (1975) is identical or not with a substance stimulating gastric acid secretion which Orloff et al. (1976) isolated and extracted from the intestinal mucosa of hogs has not yet been decided.

The present experiments showed that gastric acid secretion increased markedly without changes in the level of serum gastrin in dogs with the Roux-en-Y internal fistula but remained unchanged in those with the external fistula. This, together with the results obtained by Menguy (1961) and Wickbom et al. (1974), suggests the possible existence of some substance in the upper jejunum, which, other than gastrin, is able to stimulate gastric acid secretion, probably constituting a 
factor responsible for the mechanism of hypersecretion of gastric acid associated with biliary diversion.

\section{References}

1) Albo, R.J., Silen, W., Ruby, L., Hein, M.F. \& Harper, H.A. (1965) Studies on the mechanism of action of secretin on gastric secretion. Gastroenterology, 48, 784-789.

2) Breen, J.J., Molina, E. \& Ritchie, W.P. (1968) Effect of common bile-duct transplantation on gastric acid secretion in the dog. Brit. J. Surg., 55, 282-284.

3) Debas, H.T., Slaff, G.F. \& Grossman, M.I. (1975) Intestinal phase of gastric acid secretion. Augmentation of maximal response of Heidenhain pouch to gastrin and histamine. Gastroenterology, 68, 691-698.

4) Grossman, M.I. (1974) Candidate hormones of the gut. Gastroenterology, 67, 730-755.

5) Heimburg, R.L. \& Hallenbeck, G.A. (1964) The effect of diversion of bile to the ileum on inactivation of histamine by the liver. Fed. Proc., 23, 214. (abstract)

6) Kihl, B.O. \& Landor, J.H. (1975) Effect of biliary fistula on canine gastric secretion. J. Surg. Res., 19, 245-249.

7) Kurokawa, K. (1970) Studies on the etiologic factors of peptic ulcer with special reference to gastric acidity following functional and circulatory impairment of the liver. Jap. J. Gastroent., 67, 968-983.

8) Landor, J.H., Behringer, B.R. \& Wild, R.A. (1970) The effect of enterectomy on gastric secretion in dogs with biliary fistulas. Amer. J. Dig. Dis., 15, 633-636.

9) McArthur, M.S. \& Longmire, W.P. Jr. (1971) Peptic ulcer disease after choledochojejunostomy. Amer. J. Surg., 122, 155-158.

10) Menguy, R. (1961) Effect of biliary diversion from the small intestine on gastric secretory activity in dogs. Gastroenterology, 41, 568-571.

11) Menguy, R. (1962) Pathogenesis of the Mann-Williamson ulcer. II. Effects of pancreatobiliary shunt to ileum on liver function of dogs. Surgery, 51, 616-620.

12) Nahrwold, D.L. \& Grossman, M.I. (1967) Effect of exclusion of bile from the intestine on gastric acid secretion. Gastroenterology, 52, 667-669.

13) Orloff, M.J., Villar-Valdes, H., Abbott, A.G., Williams, R.J. \& Rosen, H. (1970) Site of origin of the hormone responsible for gastric hypersecretion associated with porta caval shunt. Surgery, 68, 202-208.

14) Orloff, M.J., Charters, A.C. \& Nakaji, N.T. (1976) Further evidence for ain intestinal phase hormone that stimulates gastric acid secretion. Surgery, 80, 145-154.

15) Silen, W., Skillman, J.J., Hein, M. \& Harper, H.A. (1962) The effect of biliary obstruction upon canine gastric secretory activity. J. Surg. Res., 2, 197-200.

16) Slaff, G. (1974) Intestinal phase of gastric acid secretion: Augmentation of maximal response of Heidenhain pouch to gastrin. Gastroenterology, 66, 656. (abstract)

17) Way, L.W., Cairns, D.W. \& Deveney, C.W. (1975) The intestinal phase of gastric secretion: A pharmacological profile of entero-oxyntin. Surgery, 77, 841-850.

18) Wickbom, G., Ello, F., Faith, M., Woodward, E.R. \& Landor, J.H. (1974) The influence of bile on canine gastric secretion. J. Surg. Res., 16, 6-12. 